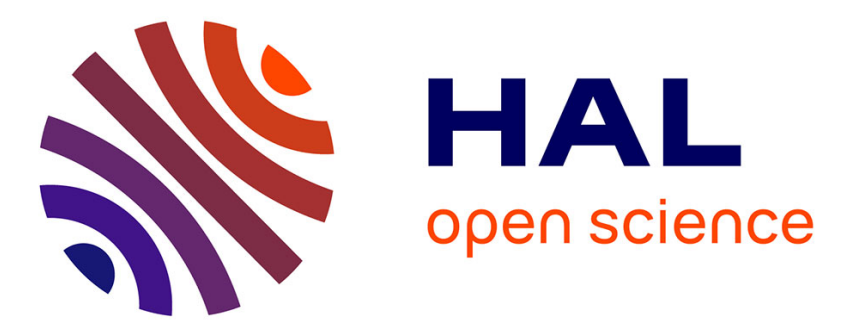

\title{
Pressure Perturbations in Deep Convection: an Experimental Study
}

D. Ramond

\section{To cite this version:}

D. Ramond. Pressure Perturbations in Deep Convection: an Experimental Study. Journal of the Atmospheric Sciences, 1978. hal-01919120

\section{HAL Id: hal-01919120 \\ https://hal.uca.fr/hal-01919120}

Submitted on 8 Jun 2021

HAL is a multi-disciplinary open access archive for the deposit and dissemination of scientific research documents, whether they are published or not. The documents may come from teaching and research institutions in France or abroad, or from public or private research centers.
L'archive ouverte pluridisciplinaire HAL, est destinée au dépôt et à la diffusion de documents scientifiques de niveau recherche, publiés ou non, émanant des établissements d'enseignement et de recherche français ou étrangers, des laboratoires publics ou privés. 


\title{
Pressure Perturbations in Deep Convection: An Experimental Study
}

\author{
D. RAMOND \\ Laboratoire Associe de Météorologie Physique,' CNRS, University of Clermont II, France
}

(Manuscript received 16 January 1978, in final form 26 May 1978)

\begin{abstract}
The pressure perturbation associated with a convective cell has been measured with an aircraft, at one level about $1500 \mathrm{~m}$ below cloud top. Agreement is found with Barnes' (1969) experimental data and with the results of the Wilhelmson's (1974) three-dimensional model of a convective cloud in a sheared environment. The efficiency of the "pressure shield" against entrainment is examined.
\end{abstract}

\section{Introduction}

The fact that pressure perturbations at ground level are induced by thunderstorms may have been noted in the very first years which followed Torricelli's experiment in 1644. Evidence of such early observations may be found, for example, in the description by Périer (1648) of the famous experiment which had been ordered by Pascal (1648) to verify the altitude-pressure relationship and had been carried out on the Puy de Dôme mountain near Clermont-Ferrand. Since that date countless observations of thunderstorm-induced pressure perturbations have been gathered. In the report of the Thunderstorm Project (Byers and Braham, 1949) the careful analysis of several well-documented case studies led to the conclusion that pressure perturbations could be attributed to dynamic, as well as to hydrostatic, processes and that they must exist in the whole depth of the convective cloud. However, only in the early 60 's, with the development of numerical models, has the role of pressure perturbations in cloud dynamics been emphasized.

So far numerous theoretical studies have been devoted to this subject, but only one experimental measurement of pressure perturbations in altitude is, to the author's knowledge, available to date. It was carried out by Barnes (1969) with a rawinsonde mesonetwork. Taking into account the comments of Davies-Jones and Ward (1971) on his experiment, Barnes (1971) evaluated to 1-2 mb the hydrostatic component of the pressure perturbations in a growing cell on the upwind flank of a developed convective storm at an altitude of about $6000 \mathrm{~m}$.

It is our intention here to give another evaluation of the pressure perturbation associated with a convective cell, as deduced from aircraft observations along a

\footnotetext{
1 L.A.M.P., Complexe Scientifique des Cézeaux, B.P. 45, 63170 Aubiere, France.

horizontal leg flown across the pressure perturbation field about $1500 \mathrm{~m}$ below cloud top.

\section{Measuring method}

The method is based on the measurement of the time variations of pressure and aircraft vertical velocity along a quasi-horizontal flight track. If the flow is assumed steady during the measurements, we can write

$$
d P / d t=\mathrm{V} \cdot \boldsymbol{\nabla} P,
$$

where $P$ is the pressure measured by the aircraft and $\mathbf{V}$ its three-dimensional velocity vector.

The pressure perturbation field is assumed to have a finite horizontal extent, and is defined by reference to an undisturbed atmosphere in hydrostatic equilibrium, i.e.,

$$
\left.\begin{array}{c}
P=P_{\mathrm{e}}=p^{\prime} \\
\partial P_{\mathrm{e}} / \partial Z=-\rho_{\mathrm{e}} g \\
\partial P_{\mathrm{e}} / \partial X=\partial P_{\mathrm{e}} / \partial y=0
\end{array}\right\} .
$$

In the above relationships, subscript $e$ refers to the undisturbed environment, $\boldsymbol{p}^{\prime}$ is the pressure perturbation and $g$ the gravity. Using (2), Eq. (1) may be written

$$
\mathbf{V} \cdot \nabla p^{\prime}=d P / d t-\left(\partial P_{e} / \partial Z\right) W_{A},
$$

where $W_{A}$ is the vertical velocity of the aircraft. If we assume steadiness of flow, relationship (3) yields

$$
d p^{\prime} / d t=d P / d t+\rho_{o} g W_{A},
$$

where the gravity $g$ is assumed constant along the quasihorizontal flight track.

If the integration is started far enough away from the disturbed zone, the initial conditions may be written

$$
\iota=0, \quad p^{\prime}=0 \quad P=P_{0} .
$$


The static pressure $P$ is directly measured by the aircraft, while its velocity $W_{A}$ is derived from a time integration of the measured vertical acceleration of the airplane. The determination of the integration constants and the elimination of bias require an adjustment of the integrated value of $W_{A}$ on the vertical velocity deduced from the pressure altitude variations at the beginning and end of the time integration, in zones which may reasonably be assumed to be undisturbed (See Appendix A). This requirement (added to the fact that the unavoidable nonlinear error occurring in the time integration procedure is a function of the time interval) suggests that the method is likely to reach the needed accuracy - $a^{\prime}$ fraction of a millibar - only when the horizontal extent of the perturbation field is sufficiently small.

Due to the expected small value of the pressure perturbation $p^{\prime}$, it appears that the application range of the proposed method must be restricted. In particular, high-turbulence conditions are likely to lead to inconclusive results as far as 1) they favor an increase of the nonlinear errors of the time integration procedure and 2) they may introduce errors in the measurements of the static pressure which on most aircraft is sensitive to side-slip angle fluctuations.

This drawback, which has been confirmed by our experimental data, seems to preclude the use of the proposed method for in-cloud tracks and may appear irremediable for our purposes.

However, the results of the three-dimensional numerical model of Wilhelmson (1974) suggest that the pressure-perturbation field associated with a convective cell in a sheared environment extends upwind well beyond the visible cloud boundary. If this assertion is justified, a pressure-perturbation could be measured aloft in the stably stratified environment just upwind of the cloud.

Referring to Wilhelmson (1974) and Wilhelmson and Ogura (1972), the horizontal extension of the pressure perturbation field is of the same order as the cell diameter. For a $5 \mathrm{~km}$ diameter cell, a leg $15 \mathrm{~km}$ in length, flown by an airplane perpendicularly to the flow and just upwind of the cell, would be long enough to encompass the perturbated field and provide the necessary measurements in the undisturbed areas on both sides of it for the adjustment procedure of the time integration.

In order to evaluate the accuracy of the method, calibration flights were made with a DC7/AMOR aircraft, ${ }^{2}$ in cloudless stably stratified conditions, near the $500 \mathrm{mb}$ level.

A set of 16 legs, $15-20 \mathrm{~km}$ in length, was selected. Ten of these legs were flown in a straight line-two of them including an altitude variation-and six in loops with a $10^{\circ}$ roll angle. The data were recorded every $0.1 \mathrm{~s}$ and the static pressure, which presented a digitali-

${ }^{2}$ The DC7/AMOR aircraft is sponsored by the Direction des Recherches et Moyens d'Essais (D.R.M.E.) and operated by the AMOR Group of the Centre d'Essais en Vol (C.E.V.) of Bretigny.
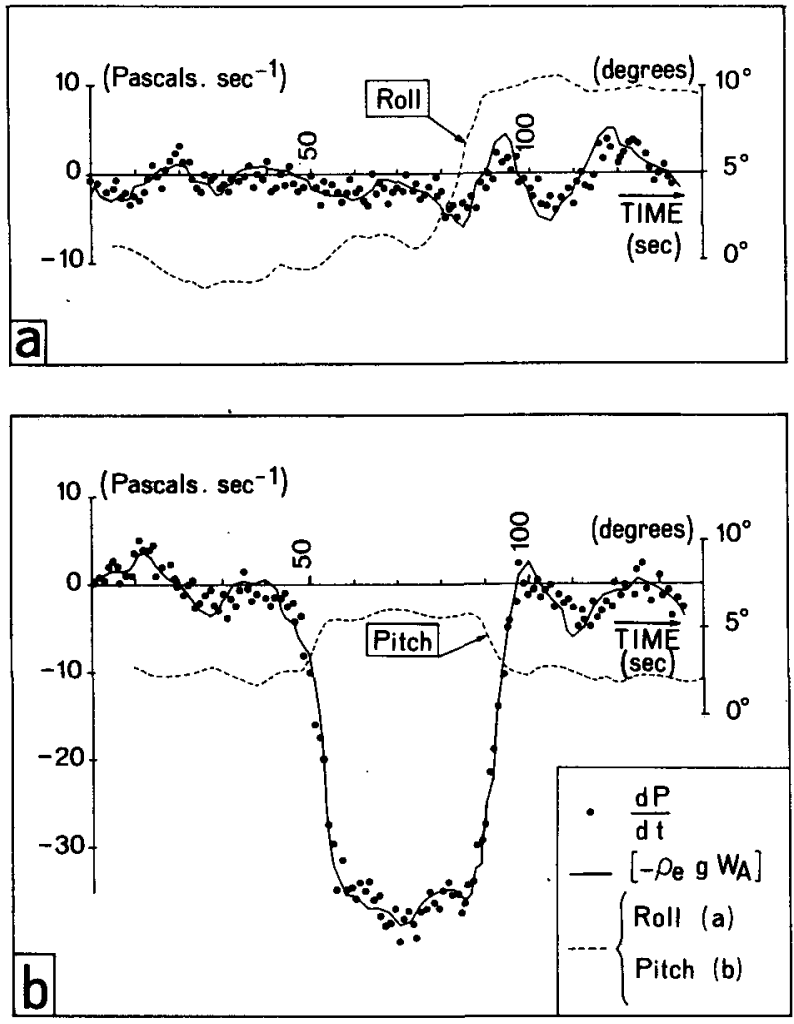

Fig. 1. Time fluctuations of $d P / d t$ and $\left(-\rho_{e} g W_{A}\right)$ along two calibration tracks representing (a) a heading variation, (b) an altitude variation. The values were computed every tenth of a second and smoothed with an 11-point unweighted running mean.

zation noise of about $0.1 \mathrm{mb}$, was smoothed with an 11-point unweighted running mean. Fig. 1 exemplifies the time variations of the two terms of the right side of (4) for two typical legs of this set.

The distribution of $p^{\prime}$ for the whole set had a quasinull expectation; the standard deviation was $20 \mathrm{~Pa}$ and the peak amplitude was less than $30 \mathrm{~Pa}$, or 0.2 and $0.3 \mathrm{mb}$, respectively.

Thus, the pressure perturbation error in the general case is expected to be about $0.3-0.4 \mathrm{mb}$ which implies that the actual pressure perturbations need to be greater than $1 \mathrm{mb}$ to give significant results with the method discussed above. According to Barnes (1969) and Wilhelmson (1974), such values are to be expected.

\section{The case study}

Measurements of the pressure-perturbation fields were made with the DC7/AMOR airplane, at $550 \mathrm{mb}$ upwind of the first cell of the multicellular ClermontFerrand storm, 23 May 1973, some aspects of which have already been studied (Ramond, 1975; Tixeront, 1976; Ramond and Tixeront, 1976).

Fig. 2 shows the radar echo contour of the cell at the measurement level $(550 \mathrm{mb})$. The streamlines of the ambient flow and the flight track are drawn in a coordinate system relative to the radar echo motion. The 
echo speed relative to the ground has been measured to within an accuracy of $1.5 \mathrm{~m} \mathrm{~s}^{-1}$ (Ramond and Tixeront, 1976). The streamlines are deduced from the DC7/AMOR Doppler winds and are drawn according to an iterative graphic method. At the time of the measurements, the cell top was reaching its maximum height, about $1500 \mathrm{~m}$ above the measurement level. The mean shear in the cloud layer was $3 \times 10^{-3} \mathrm{~s}^{-1}$ and the variation in the wind direction was less than $20^{\circ}$ in the troposphere depth. Evidence of a convergence zone on the upwind flank of the cell was infered from the analysis of the wind field measured inside the cloud (Ramond, 1977), the representativeness of which is discussed in Appendix B.

The general streamline pattern presents some analogy with the flow around a solid cylinder: the ambient flow is decelerated upwind and deflected around the cloud; it is accelerated in the vicinity of the lateral flanks and converges downwind. The moderate turbulence encountered in zone $B$ suggests the presence of a wakelike flow downwind of the cell. In zone A, a $50 \%$ increase of the mixing ratio and a $1 \mathrm{~K}$ decrease of the potential temperature were measured and are attributed to erosion or detrainment processes (Ramond, 1977).

Fig. 3 shows the variations of the pressure perturba- tions along the upwind leg represented in Fig. 2, and according to the measurement method described above. The computations were made every $0.1 \mathrm{~s}$ and the results were smoothed with an 11-point unweighted running mean. The regions noted I and II on Fig. 3 are those where the adjustments of the integrated values were performed. The maximum amplitude of the pressure perturbation is $1.7 \mathrm{mb}$, which is significantly greater than the expected $0.4 \mathrm{mb}$ error. As a check, Fig. 4 presents the time fluctuations of the two terms of the right side of Eq. (4) along the flight track. The zones designated by $A$ and $B$ are zones where strong pressure perturbation gradients, positive and negative respectively, were encountered by the DC7/AMOR airplane. A comparison with Fig. 1 shows that in these zones, the gap between the two curves is much greater than the noise in the reference cases of Fig. 1. Moreover, it is the pressure term fluctuations which indeed appear to create these extended gaps.

The preceding results are in agreement with Barnes' $(1969,1971)$ data and tend to confirm those of Wilhelmson (1974) concerning the pressure-perturbation field in a sheared environment. Referring to Barnes $(1969,1971)$, such a perturbation field would constitute

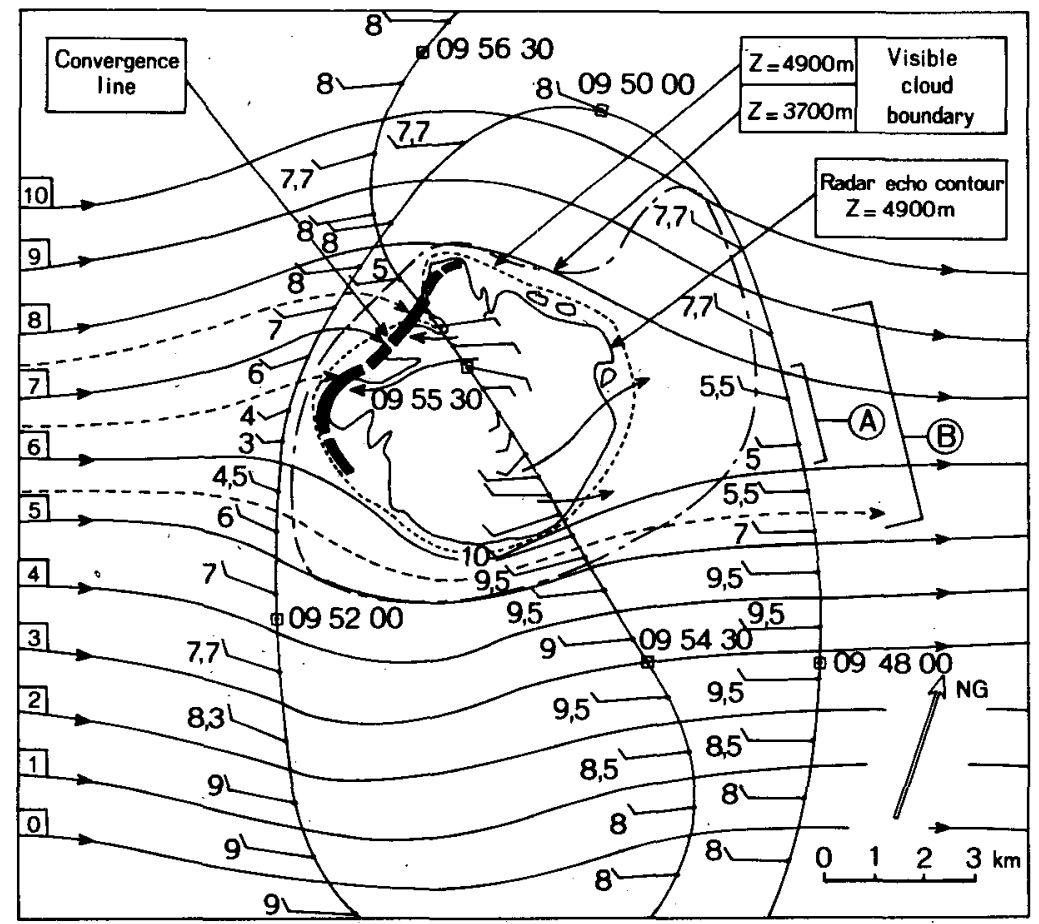

FIG. 2. Horizontal wind field and streamlines at $550 \mathrm{mb}$ around the first cell of the Clermont-Ferrand storm, 23 May 1973. The AMOR/DC7 flight track and the wind vectors are drawn in a relative coordinate system attached to the cell, represented here by its radar echo contour at 0954:30 and the flight level. The number drawn close to each relative wind vector indicates its speed. The drawing of the convergence line (heavy dashed line) is only indicative: it schematizes a convergence zone located near the upwind flank, the evidence of which is derived from the analysis of the relative wind field inside the cloud as well as outside. 


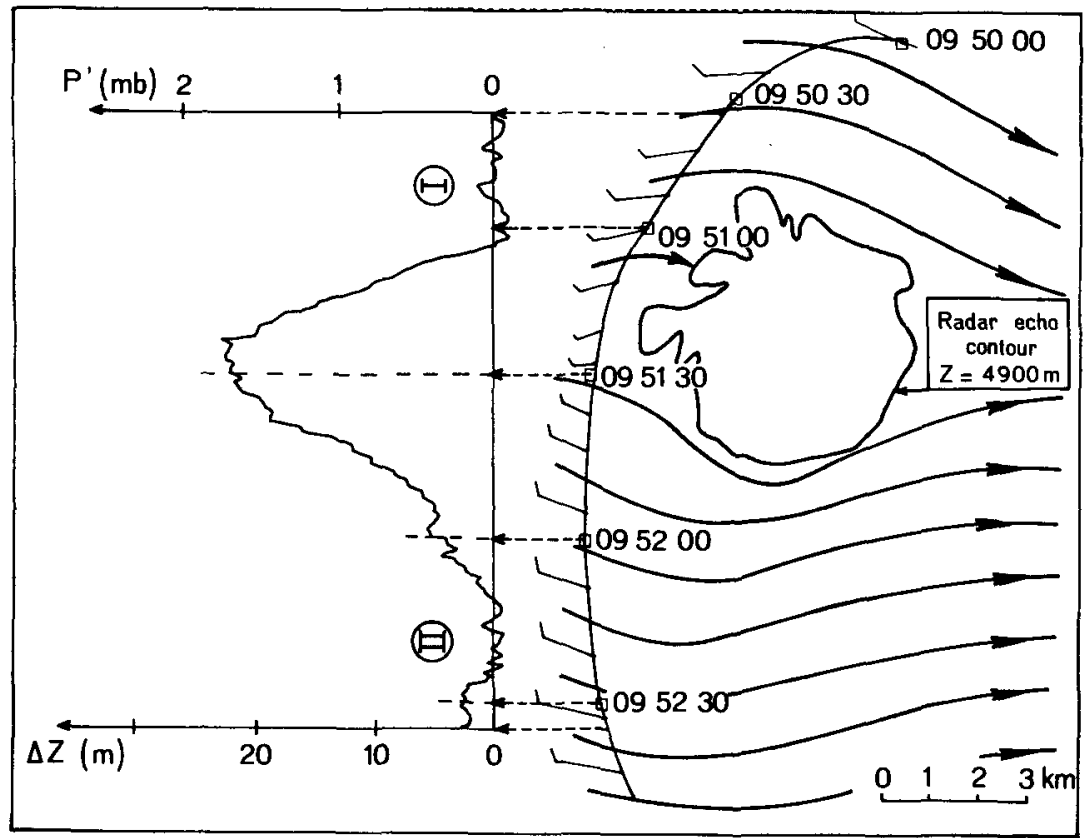

Fic. 3. Pressure perturbation $p^{\prime}$, measured both in millibars and in meters at flight level, on the upwind flank of the first cell of the Clermont-Ferrand storm, 23 May 1973. A part of Fig. 2 has been drawn on the right of the figure.

a "pressure shield" protecting the updraft core from the ambient flux.

\section{The pressure-shield efficiency}

As proposed by Barnes (1969, 1971), the pressure shield efficiency may be characterized by a "stopping distance," which is the distance necessary for an ambient air particle, located near the vertical plane of symmetry of the flow, to be stopped by the adverse pressureperturbation gradient force. If $X_{0}$ refers to this stopping distance, and if we assume a linear pressure-perturba-

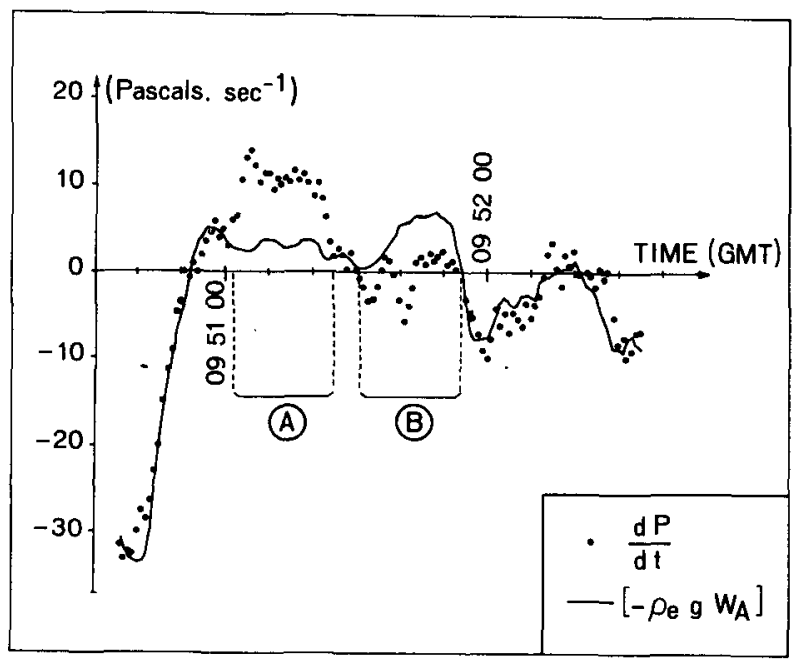

Frg. 4. Time fluctuations of $d P / d t$ and $\left(-\rho_{e} g W_{A}\right)$ along the upwind leg of the case study. The scales are identical to Fig. 1. tion gradient, we can write

$$
\frac{1}{2} \rho v^{2}=\left(P_{\max }^{\prime} / \Delta x\right) X_{0},
$$

which expresses the equality between the kinetic energy lost by the particle and the work done against the pressure gradient; $\rho$ is the density of the particle, $v$ its horizontal velocity relative to the cloud at infinity upwind, $P_{\max }^{\prime}$ the maximum value of the pressure-perturbation field, and $\Delta x$ its horizontal extension upwind. If $P_{\max }^{\prime}$ is taken typically equal to $100 \mathrm{~Pa}$, and $\rho$ to $0.7 \mathrm{~kg}$ $\mathrm{m}^{-3}$, we can see from Eq. (6) that a $17 \mathrm{~m} \mathrm{~s}^{-1}$ relative speed would be necessary for the particle to reach the center of the pressure-perturbation field $\left(X_{0}=\Delta x\right)$. Such a relative velocity is only to be encountered in extreme shear conditions. Assuming in the case study of Figs. 2 and 3 that the horizontal gradient in the plane of symmetry is of the same magnitude as the gradients measured perpendicular to it $\left(\partial P^{\prime} / \partial x=\partial P^{\prime} / \partial y=0.04 \mathrm{~Pa}\right.$ $\left.\mathrm{m}^{-1}\right), X_{0}$ may be estimated at $600 \mathrm{~m}$. That is to say, an ambient air particle located in the vicinity of the plane of symmetry would not even be able to reach the visible cloud boundary, since the relative velocity, from Figs. 2 and 3 , appears to be no more that $4 \mathrm{~m} \mathrm{~s}^{-1}$ at a distance of $500 \mathrm{~m}$ upwind of the visible cloud boundary. The particles located away from the plane of symmetry of the flow are partly decelerated, and partly deflected around the cloud.

From the preceeding, it may be inferred that there exists, at least in the upper part of a convective cell, a null flux surface, upwind of the cloud core, that may be compared to a solid surface protecting the cloud core from the environment flux. If the vertical wind shear 
is not extreme, this surface may even be located outside and upwind of the visible cloud boundary, as it appears to be in our case study where the shear was $3 \times 10^{-3} \mathrm{~s}^{-1}$.

\section{Conclusions}

The data analyzed above have shown that, at least at one level in the upper part of a convective cell and at the end of its growing stage, a positive pressure-perturbation constitutes an efficient protection of the cloud against the ambient flux. This protection is likely to be effective over a large part of the depth of the cell, since Barnes (1969) and Wilhelmson (1974) have shown that the perturbation is positive over other cloud levels. This would be in agreement with the results of DaviesJones (1974) who showed that the thunderstorm updraft cores were undiluted. The existence of a null flux surface, and its analogy with a solid surface, lend support to the attempts that have been made to formulate the horizontal momentum transfers between a cloud and its environment in terms of a drag force through the definition of a drag coefficient (Hischtfeld, 1960; Fujita and Grandoso, 1968, etc). A further extension of the analogy has led several researchers (Newton and Newton, 1959; Alberty, 1969) to consider the dynamic pressure, resulting from the relative motion of the cloud and the environmental flow, as an important factor in the persistence and regeneration processes of large convective currents. An estimate of the dynamic pressure in our case study may be computed by using Eq. (6) with $X_{0}=\Delta x$, and taking for the relative wind the highest value $\left(9 \mathrm{~m} \mathrm{~s}^{-1}\right)$ measured during the upwind flight track, at a distance from the cloud (cf. Fig. 2). It results that the contribution of this dynamic pressure to the total pressure perturbation is only $0.3 \mathrm{mb}$ out of the measured $1.7 \mathrm{mb}$. This suggests that the conclusions concerning the role of the dynamic pressure, considered alone, should be reconsidered and extended in a more general context including all the pressure-perturbation components, i.e., the dynamic, the hydrostatic and the precipitation-drag-induced components.

\section{APPENDIX A}

\section{Vertical Acceleration}

The DC7/AMOR airplane is equipped with a $0-2 \mathrm{~g}$ accelerometer located close to the center of mass with its axis perpendicular to the longitudinal axis of the airplane and within the plane of symmetry. Due to rolling and pitching motion this axis is not generally vertical and the measurement of the vertical acceleration requires the knowledge of the direction of the true acceleration vector. The following two assumptions are made:

1) The true acceleration is assumed to be perpendicular to the true airspeed vector, which implies that the contribution of the longitudinal accelerations is neglected, but that the centripetal accelerations are taken in account. The smaller the pitch angle, the better this assumption is verified.

2) The resulting acceleration of the gravity vector $g \mathbf{k}$ and the true acceleration vector is assumed to lie within the plane of symmetry of the airplane. Such an assumption implies that the side-slip angle is null and that the roll angle adapts itself so that the force system applied to the airplane remains symmetric.

These assumptions may be considered to be verified when the actual flight conditions are as follows:

- Quasi-horizontal flight in low turbulence. (Incidence and pitch angles approximately equal and $<4^{\circ}$ ).

- Constant power setting (longitudinal acceleration reduced).

- Pilot action as smooth as possible and roll angle always less than $10^{\circ}$ (side-slip angle as close to zero as possible).

The data which are analysed in this paper were recorded in such conditions.

The airplane vertical acceleration $\Gamma_{Z}$ is then given by

$\Gamma_{Z}=\Gamma_{m}(\sin \theta \tan \alpha+\cos \theta \cos \phi)$

$$
-g \cos \theta[\cos \theta+\sin \theta \tan \alpha \cos \phi] \text {, }
$$

where $\Gamma_{m}$ is the measured acceleration, $\theta, \alpha$ and $\phi$ are, respectively, the pitch, incidence and roll angles, and $g$ is the gravity at the location and level of the flight.

It will be noted that an error in the incidence angle $\alpha$ (i.e., on the direction of the true acceleration) does not significantly affect the values of $\Gamma_{z}$. In the flight conditions described above, an error of $2^{\circ}$ in $\alpha$ would yield an error in $\Gamma_{Z}$ much less than $2 \times 10^{-3} \mathrm{~m} \mathrm{~s}^{-2}$, which, were it systematic over a. $2 \mathrm{mn}$ integration interval, would in turn yield an error in the aircraft vertical velocity $W_{A}$ of less than $0.25 \mathrm{~m} \mathrm{~s}^{-1}$ at the end of the integration. This remark shows that the first assumption made above is not critical for the accuracy of the method. In any case, part of such a systematic error in $W_{A}$ is eliminated by the procedure of adjustment described in the following.

\section{a. Integration adjustment procedure}

It is well known that instrumental errors in the measured values of the acceleration and errors in the evaluation of gravity cause time variations in the computation of vertical velocity and altitude by integration of the vertical acceleration. In our case the bias may be increased by the fact that the acceleration is not measured along a vertical axis. This bias is generally removed by a continuous adjustment of the computed altitude based on the independently measured pressure altitude. As far as we are considering pressure perturbations, such an adjustment is only possible in zones where the perturbations may be reasonably assumed to vanish, that is to say, in zones located far away from 


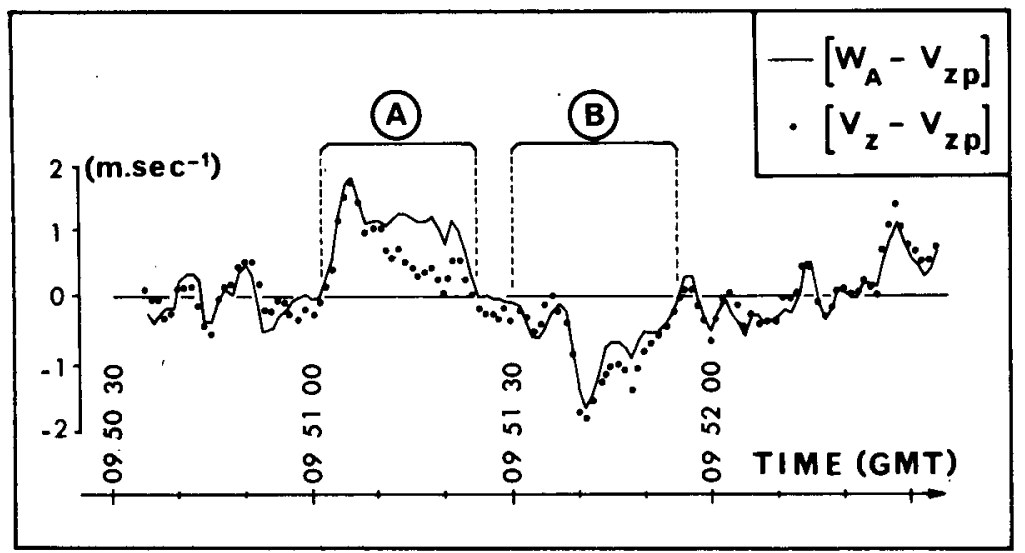

FIG. 5. Comparison of the differences $\left(W_{A}-V_{Z P}\right)$ and $\left(V_{Z}-V_{Z P}\right)$ during the upwind flight track drawn on Fig. 3. $W_{A}$ is the integrated aircraft vertical velocity, $V_{Z}$ the vertical component of the true airspeed, and $V_{Z P}$ the time derivative of the pressure altitude. The data have been smoothed with an 11-point running mean.

the studied cloud at the beginning and at the end of the time integration interval. On the other hand, since the integration intervals we are dealing with are small ( $<3 \mathrm{~min}$ ), the inherent error in the computed altitude which exhibits an exponentially increasing tendency with time may be approximated by a parabolic law.

The aircraft vertical velocity $W_{A}$ and altitude $Z_{A}$ are thus computed according to

$$
\begin{aligned}
W_{A} & =\int_{0}^{t} \Gamma_{Z} d t+W_{0}-k t, \\
Z_{A} & =\int_{0}^{t}\left[\int_{0}^{t} \Gamma_{Z} d t\right] d t+W_{0} t+Z_{0}{ }^{\prime}-\frac{1}{2} k t^{2},
\end{aligned}
$$

where $W_{0}$ and $Z_{0}$ are integration constants and $k$ the bias coefficient.

As a first step, the integration is carried out with $k=0$ and the values of $W_{0}$ and $Z_{0}$ are computed through a least-square fitting of $Z_{A}$ and the pressure altitude $Z_{P}$ on a $10 \mathrm{~s}$ interval at the beginning of the integration. Each value is computed every tenth of a second and the fitting is performed over a 100-point set. In a second step, the values of $W_{0}$ and $Z_{0}$ are introduced in the integration and an evaluation of $k$ is made through a least-square fitting of $Z_{A}$ and $Z_{P}$ on a $10 \mathrm{~s}$ interval at the end of the total integration interval. Step 1 is repeated with this first estimation of $k$, and $W_{0}$ and $Z_{0}$ are recomputed, and so on. The iteration is stopped when two successive values of $W_{0}, Z_{0}$ and $k$ differ respectively by less than $0.05 \mathrm{~m} \mathrm{~s}^{-1}, 0.5 \mathrm{~m}$ and $5 \times 10^{-4}$ $\mathrm{m} \mathrm{s}^{-2}$.

\section{b. Method accuracy}

The calibration data from which Fig. 1 has been extracted show that in a stably stratified environment where the pitch angle is less than $5^{\circ}$ and the roll angle $<10^{\circ}$, the accuracy of the integrated vertical velocity
$W_{A}$ is better than $\pm 0.4 \mathrm{~m} \mathrm{~s}^{-1}$ for a 2 min integration interval.

In a turbulent environment, the longitudinal acceleration and the side-slip angle may not be neglected and the accuracy of the method deteriorates.

However, the data which are discussed in this paper refer to a flight leg upwind of a convective cell where no turbulence was reported and indeed the corresponding acceleration recordings are smooth. A $\pm 0.4 \mathrm{~m} \mathrm{~s}^{-1}$ accuracy on the aircraft vertical velocity may then be assumed during this leg. Nevertheless, a further check has been made by computing the airplane vertical velocity $V_{Z}$ relative to air from the general expression

$$
\begin{array}{r}
V_{Z}=V_{a}(\sin \theta \cos \alpha \cos \beta-\cos \theta \sin \phi \sin \beta \\
-\cos \theta \cos \phi \sin \alpha \cos \beta),
\end{array}
$$

where $V_{a}$ is the true air speed and $\beta$ the side-slip angle.

In Fig. $5, W_{Z}$ and $V_{Z}$ are compared to the time derivative $V_{Z P}$ of the pressure altitude. Each value has been computed every tenth of a second and $V_{Z P}$ was smoothed with an 11-point unweighted running mean. It can be seen that the behavior of $W_{A}$ and $V_{Z}$ is very similar in zones A and B where the maximum horizontal pressure gradients have been computed (cf. Figs. 3 and 4). The space between the two curves drawn on Fig. 5 is a measure of the air vertical velocity. Its maximum value is about $1 \mathrm{~m} \mathrm{~s}^{-1}$ in zone $A$.

Replacing $W_{A}$ by $V_{Z}$ in relation (4) (i.e., neglecting air motion) yields a pressure perturbation maximum of $1.1 \mathrm{mb}$ at the end of zone $\mathrm{A}$, a value which is to be compared to $1.7 \mathrm{mb}$ obtained with $W_{A}$, and which is already well above the expected noise.

\section{APPENDIX B \\ Horizontal Winds}

For the experiment described in this paper, the horizontal winds are computed from the AMOR/DC7 


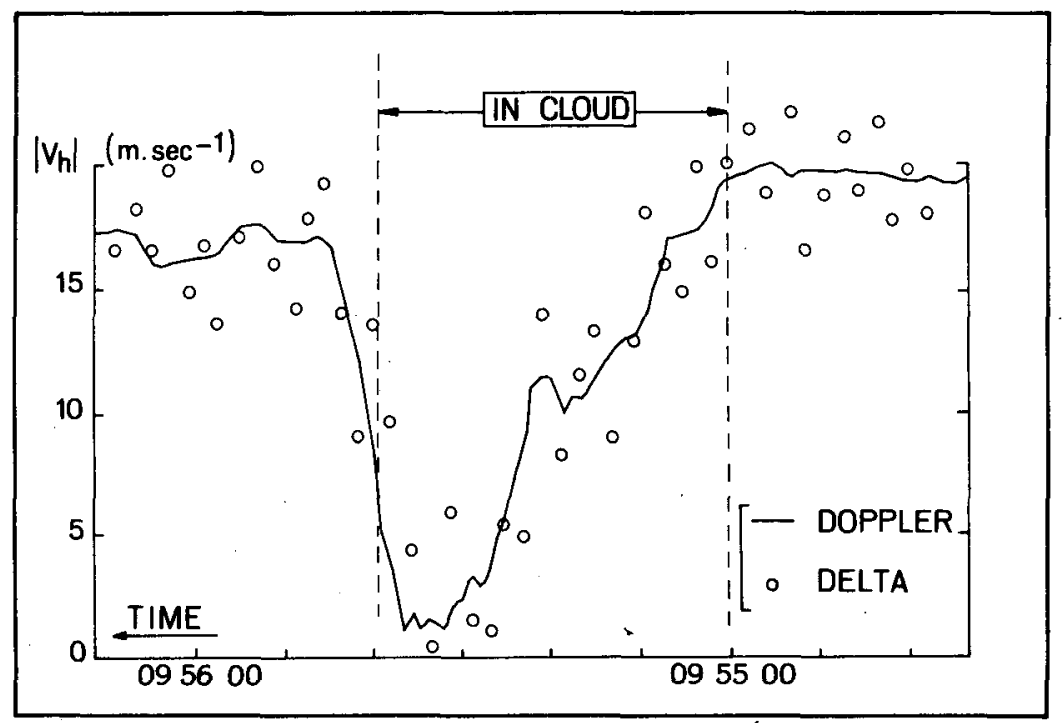

FIG, 6. Comparison of the horizontal winds computed from the Doppler Navigation System and the DELTA localization system during the incloud flight presented in Fig. 2.

Doppler Navigation System data. This system is accurately calibrated during the flight, using a method discussed by Gayet (1973), which is similar to that proposed by Fujita (1966). Computations of the winds are made every $0.1 \mathrm{~s}$ and the winds are arithmetically averaged over a second, before being smoothed with a 5-point (i.e., $4 \mathrm{~s}$ ), unweighted running mean.

Under the conditions of the experiment the accuracy of the absolute Doppler wind vectors, outside the cloud, is estimated to $1 \mathrm{~m} \mathrm{~s}^{-1}$ in speed and $5^{\circ}$ in direction. Inside the cloud, as noted by Fujita (1966), the Doppler winds may be affected by the presence of hydrometeors in the Doppler radar beams. In order to check the representativeness of the Doppler winds inside the cell which is presented on Fig. 2, an attempt was made to recompute the winds using an accurate localization system instead of the Doppler Navigation System. The DELTA localization system which was operated by the AMOR Group and was still a prototype at the time of the experiment, consists of four active radio beacons, about $100 \mathrm{~km}$ apart and located at known geodesic points. Every tenth of a second an onboard phase comparator gave the distances of the four beacons from the AMOR/DC7 aircraft. With such a system, and without any propagation corrections, the absolute $x-y$ position of the aircraft is computed to an accuracy better than $50 \mathrm{~m}$. However, over a short distance, the relative error between two positions of the aircraft is estimated to be less than $5 \mathrm{~m}$. Along the track flown between 0954:30 and 0956:10 (cf. Fig. 2), averaged values of the aircraft velocity relative to earth and of the drift angle were computed every $2 \mathrm{~s}$ by comparing the positions of the aircraft at the preceding and the following seconds, and by the use of the aircraft heading recordings. Knowing the corresponding average velocity relative to air, which is measured independently, the navigation triangles can be built up, and the winds computed. In Fig. 6 the speed of these winds, smoothed with a 3 -point unweighted running mean, are compared with the Doppler wind speeds. The global agreement of the two computed winds leads to the conclusion that, in this particular case, the presence of hydrometeors within the Doppler beams did not affect the resulting data. A similar conclusion has also been reached, but indirectly, by Ramond (1975) through the analysis of the winds along a leg flown just above the top of the same cell, a few minutes latter. The wind vectors shown in Fig. 2 are relative to the radar echo motion at flight level. The latter has been evaluated from successive photographs of the AMOR/ DC7 radar scope according to the method described by Ramond and Tixeront (1976). Due to the accuracy of the DELTA localization system, the motion of the radar echo is known to about $1.5 \mathrm{~m} \mathrm{~s}^{-1}$ in speed and $5^{\circ}$ in direction. Ramond and Tixeront (1976) have also shown that the zone inside the cloud where the relative horizontal component is directed upwind (cf. Fig. 2) corresponds to the updraft, while the downdraft is located in the zone where the relative horizontal component is directed downwind.

Acknowledgments. I am deeply indebted to the Direction des Recherches et Moyens d'Essais (D.R.M.E) for having placed the AMOR/DC7 to my disposal for this experiment, and to the AMOR Group which operated it, competently and obligingly. My thanks go also to Pr. R. G. Soulage for his most useful advice. 


\section{REFERENCES}

Alberty, R. L., 1969: A porposed mechanism for cumulonimbus persistence in the presence of strong vertical shear. Mon. Wea. Rev., 97, 590-596.

Barnes, S. L., 1969: Some aspects of a severe, right moving thunderstorm, deduced from mesonetwork rawinsonde observations. J. Atmos. Sci., 27, 634-648.

- 1971 : Reply (to Davies-Jones and Ward). J. Atmos. Sci., 28, 653-654.

Byers, H. R., and R. R. Braham, 1949: The Thunderstorm. Rep. from the Thunderstorm Project, U. S. Weather Bureau, Washington, D. C. 287 pp.

Davies-Jones, R. P., 1974: Discussion of measurements inside high-speed thunderstorm updrafts. J. Appl. Meteor., 13, 710-717.

- - and N. B. Ward, 1971: Comments on some aspects of a severe right-moving thunderstorm deduced from mesonetwork rawinsonde observations. J. Atmos. Sci., 18, 652-653.

Fujita, T., 1966: Accurate calibration of Doppler winds for their use in the computation of mesoscale winds. Mon. Wea. Rev., 94, 19-35.

Fujita, T., and H. Grandoso, 1968: Split of a thunderstorm into anticyclonic and cyclonic storms and their motion as determined from numerical model experiments. J. Atmos. Sci., 25, 416-439.

Gayet, J. F., 1973: Mesures des paramètres thermodynamiques et dynamiques de l'atmosphère au moyen d'un DC7/AMOR (Eté 1972). Diplôme d'Etudes Approfondies, Université de Clermont-Ferrand, 72 pp. [Available at L.D.M.A., B.P. 45, 63170 Aubière.]

Hischtfeld, W., 1960: The motion and erosion of convective storms in severe vertical wind shear. J. Meteor., 17, 272-282.
Newton, C. W., and H. R. Newton, 1959 : Dynamical interactions between large convective clouds and environment with vertical shear. J. Meteor., 16, 483-496.

Pascal, B., 1648: See Périer, 1648.

Périer, F., 1648: "Récit de la grande expérience de l'équilibre des liqueurs projetée par le Sieur Blaise Pascal, pour l'accomplissement du Traicté qu'il a promis dans son abbrégé touchant le Vuide, et faite par le Sieur F. Périer en une des plus hautes montagnes d'Auvergne. A Paris chez Charles Saureux, Relieur Ordinaire du Chapitre, rue neusve N.-Dame, proche Saincte Geneviesve des Ardenrs, aux Trois Verius, 22 pp. Ramond, D., 1975: Variations du vent horizontal à l'intérieur de cellules convectives. J. Rech. Atmos., 9, 77-85.

- 1977: Rôle des perturbations de pression dans l'interaction d'un nuage convectif et de son environnement: étude expérimentale et paramétrisation. Thèse de Doctorat d'Etat. Laboratoire Associé de Météorologie Physique, Université de Clermont II. [Available at Université de Clermont II, 63170 Aubière, France.

- - and D. Tixeront, 1976: Discontinuous aspects of the growth of a cloud from $\mathrm{CuCg}$ to $\mathrm{CuCb}$ state." Preprints Int. Cloud Phys. Conf., Boulder, Amer. Meteor. Soc., 413-319.

Tixeront, D., 1976: Développement rétrograde et pulsatoire d'un cumulonimbus. Thèse de Doctorat d'Ingénieur, Université de Clermont II, 120 pp. [Available at Université de Clermont II, 63170 Aubière, France.]

Wilhelmson, R., 1974: The life cycle of a thunderstorm in three dimensions. J. Almos. Sci., 31, 1629-1651.

cal modeling of a cloud. J. Atmos. Sci., 29, 1295-1307. 